FAST WAVE ANTENNA ARRAY FEED CIRCUITS

TOLERANT OF TIME-VARYING LOADING FOR DIII-D

RECEIVED

JUN 161997

by

ostitit

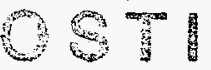

R.I. PINSKER, C.P. MOELLER, J.S. deGRASSIE, D.A. PHELPS, C.C. PETTY, R.W. CALLIS, and F.W. BAITY

Wh1? 1 की

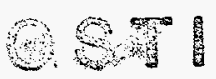

MASTER

DISTRIBUTION OF THIS DOCUMENT IS UNLIMITES

APRIL 1997 


\section{DISCLAIMER}

This report was prepared as an account of work sponsored by an agency of the United States Government. Neither the United States Government nor any agency thereof, nor any of their employees, make any warranty, express or implied, or assumes any legal liability or responsibility for the accuracy, completeness, or usefulness of any information, apparatus, product, or process disclosed, or represents that its use would not infringe privately owned rights. Reference herein to any specific commercial product, process, or service by trade name, trademark, manufacturer, or otherwise does not necessarily constitute or imply its endorsement, recommendation, or favoring by the United States Government or any agency thereof. The views and opinions of authors expressed herein do not necessarily state or reflect those of the United States Government or any agency thereof. 


\section{DISCLAIMIER}

Portions of this document may be illegible in electronic image products. Images are produced from the best available original document. 


\title{
FAST WAVE ANTENNA ARRAY FEED CIRCUITS TOLERANT OF TIME-VARYING LOADING FOR DIII-D
}

\author{
by \\ R.I. PINSKER, C.P. MOELLER, J.S. deGRASSIE, \\ D.A. PHELPS, C.C. PETTY, R.W. CALLIS, \\ and F.W. BAITY*
}

This is a preprint of a paper presented at the 12th Topical Conference on Radio Frequency Power in Plasmas, April 1-3, 1997, Savannah, Georgia, and to be printed in the Proceedings.

\author{
Work supported by \\ U.S. Department of Energy Contracts \\ DE-AC03-89ER51114 and DE-AC05-960R22464
}

*Oak Ridge National Laboratory

GENERAL ATOMICS PROJECT 3466

APRIL 1997 


\title{
Fast Wave Antenna Array Feed Circuits Tolerant of Time-Varying Loading for DIII-D
}

\author{
R.I. Pinsker, C.P. Moeller, J.S. deGrassie, D.A. Phelps, \\ C.C. Petty, R.W. Callis, and F.W. Baity* \\ General Atomics, San Diego, California 92186 \\ * Oak Ridge National Laboratory, Oak Ridge, Tennessee 37831
}

\begin{abstract}
Three different transmission line configurations for operating a fourelement antenna array with a single rf power source are compared. The goal of this study is to obtain a system that presents a matched load to the generator despite variation of the loading of the array elements due to changing plasma conditions.
\end{abstract}

Phased arrays of loop antennas with four identical elements are used to launch fast waves in several tokamak devices. At DIII-D, each of the three arrays of four elements is connected to a single $2 \mathrm{MW}$ amplifier. Driving four elements with a single source requires that not only impedance matching, but also all of the power division and phase control functions, be performed at high power. Since conventional variable high power transmission line components (phase shifters and tuning stubs) cannot be moved rapidly, simultaneously maintaining an adequate impedance match, phase control, and an optimal distribution of antenna currents among the array elements is difficult, due to the substantial and rapid variations in the plasma loading of the antennas during a tokamak discharge. These variations, for example, due to L/H-mode transitions or ELMs, affect not only the resistive antenna loading, but also both the self- and mutual reactive components.

With a conventional transmission line system, all the parameters of which are fixed during a discharge, these loading variations cause the if source to experience a rapidly changing load impedance which in turn leads to reduction of the available if power. The high power tetrodes used in these amplifiers are generally specified to be able to maintain full power into a voltage reflection coefficient up to $17 \%-20 \%$. Hence, our goal is to design a transmission line system that is capable of passively maintaining this low reflection coefficient at the generator despite variations in the antenna loading, while providing adequate antenna current balance and phase control. We shall refer to this desired property as "robustness." For this study, we consider only a fixed frequency system, allowing the use of simple, narrow- 
band components, such as single-stage quarter wave transformers. In these calculations we will use the parameters of the $60 \mathrm{MHz}$ system presently in use on DIII-D [1]. Another goal is to minimize the number of moveable transmission line elements, as experience has shown that these components are often among the most trouble-prone in these systems. These goals are to be achieved without significant modification of the four-element array itself; we have already shown on the JFT-2M tokamak that an array of twelve elements with the power flow from element to element via their mutual reactance (a "combline") easily achieves these goals [2].

To provide a basis of comparison, the first configuration considered is a relatively conventional system, shown in Fig. 1. A four-port decoupler, consisting of three crosslines with stub adjustments, is used to cancel the nearest neighbor mutual reactances in the antenna. To minimize the number of variable tuning elements, four identical sections of high impedance transmission lines one-quarter of a wavelength long $(125 \mathrm{~cm}$ at $60 \mathrm{MHz})$ are used to produce a sufficiently low standing wave ratio in the three phaseshifters that phase control is possible above a minimum value of resistive loading. Four-way power division is obtained with a five-arm matched tee to provide a nominal match to the transmitter, which is tuned to the $50 \Omega$ characteristic impedance of the balance of the transmission lines. A stub and phaseshifter is used at the transmitter output so that a match can be obtained for loadings other than the one for which the transformers are optimal.

The second configuration ("split," shown in Fig. 2) is a tunerless version of the systems presently in use on DIII-D [3], in which a $90^{\circ} 3 \mathrm{~dB}$ hybrid junction is used to provide power division and transmitter isolation against any resistive or self-reactive load change that affects all four array elements identically. This system can produce current drive phasing $\left[0^{\circ}, 90^{\circ}, 180^{\circ}, 270^{\circ}\right]$ or counter current drive by interchanging the transmitter and dummy load connections to the hybrid with a switch. The addition of a phase shifter to either output of the hybrid junction would permit the symmetric phasings $\left[0^{\circ}, 180^{\circ}, 180^{\circ}, 0^{\circ}\right]$ and $\left[0^{\circ}, 0^{\circ}, 180^{\circ}, 180^{\circ}\right]$, but the robustness of the system disappears in these phasings, so that a tuner at the transmitter output would be required to make use of these phasings.

In the third configuration, we adapt the traveling wave antenna ("TWA," Fig. 3) concept [4] to high power operation of a four element array. This configuration is described in more detail elsewhere in this volume [5]. Since the hybrid junction does not provide isolation for the transmitter in this case, a tuner is provided near the transmitter output as in the first configuration. As in the split case, the direction of the antenna phasing can be reversed by interchanging the transmitter and dummy load ports. However, unlike the split case, other uniform phasings $\left(e . g .,\left[0^{\circ}, 60^{\circ}, 120^{\circ}, 180^{\circ}\right]\right)$ are accessible by changing the transmitter frequency in a narrow band about $2 \mathrm{MHz}$ wide.

The parameters used to model the array elements in the $60 \mathrm{MHz}$ system are derived from low power network analyzer measurements in the absence of plasma, combined with measurements of the resistive and reactive antenna loading obtained during high power operation into tokamak plasmas from 1991-1996. We take as the nominal antenna loading $R=1.75 \Omega$ (typical of $L$-mode loading at a small 
antenna-plasma gap), the reactive loading relative to the vacuum (no plasma) values of $\left(L-L_{\mathrm{vac}}\right) / L_{\mathrm{vac}}=-0.16$ and $M / M_{\mathrm{vac}}=0.5$, and the resonant lines, decouplers, and transmitter tuners all are adjusted to match this nominal condition.

First, we study the effect of separately varying $R, L$, and $M$. in the three configurations, in current drive phasing (Fig. 4). The TWA and split configurations are much more robust than the conventional case for variations of $R$ and $L$. However, all three systems are comparably sensitive to variations in mutual reactance between the antenna elements; there was no compensation for this variation with the decoupler stubs in the conventional and split cases.

Next, we study the robustness of the three systems to simultaneous variation of $R, L$, and $M$. In the scans shown in Fig. 5, the reactive quantities are assumed to increase linearly as the resistive loading decreases, with slopes suggested by experimental data. For the conventional and TWA cases, several different antenna phasings are considered; in each loading scan, the transmitter tuner is fixed at a match position for the nominal loading point. Evidently, the TWA is somewhat more robust than the conventional system for any phasing in the range of $60^{\circ}$ to $120^{\circ}$, particularly at light resistive/heavier reactive loading. Neither system is as robust as the split configuration, which however can be used only for co- or counter-current drive phasings.

We conclude that the conventional system, with the largest number of adjustable tuning elements, is indeed the most flexible but the least robust of the three systems. The split configuration with only one tuning adjustment is the most robust and least flexible system. The TWA is nearly as robust as the split configuration when $90^{\circ}$ phasing is used, but also permits a range of uniform antenna phasings between $60^{\circ}$ and $120^{\circ}$, albeit with reduced robustness compared with the optimal, $90^{\circ}$ phasing. Hence, we are testing the split configuration on one array on DIII-D (the $60 \mathrm{MHz}$ system) in 1997, and the TWA in FY98 on the same array that had been used for low power tests of this configuration [4].

This is a report of work sponsored by U.S. Department of Energy Contracts DE-AC03-89ER51114 and DE-AC05-960R22464.

\section{REFERENCES}

1. C.C. Petty et al., Nucl. Fusion 35, 773 (1995).

2. R.I. Pinsker et al., "Development of Fast Wave Systems Tolerant of Time-Varying Loading," in Proc. 19th Symp. on Fusion Technology, Lisbon, 1996, to be published.

3. J.S. deGrassie, R.I. Pinsker, W.P. Cary, et al., " 4 MW Upgrade to the DIII-D Fast Wave Current Drive System," in Proc. 15th IEEE/NPSS Symp. on Fusion Engineering, Hyannis, MA, 1993, vol. II, p. 1073.

4. H. Ikezi and D.A. Phelps, Fusion Technology 31, 106 (1997).

5. D.A. Phelps et al., "Advantages of Traveling Wave Resonant TWA for Fast Wave Heating Systems," these proceedings. 


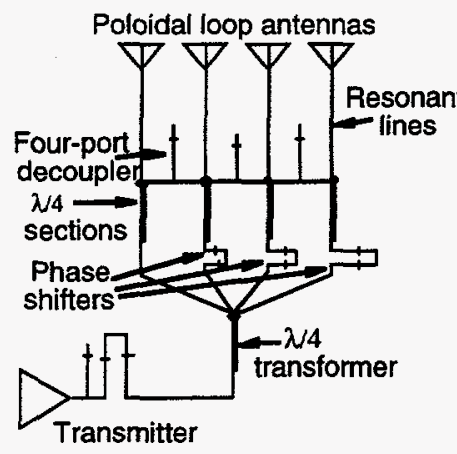

FIGURE 1.

"Conventional" system for driving a 4-element phased array with a single if source.

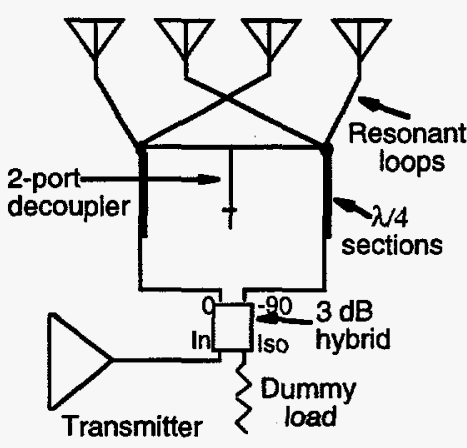

FIGURE 2. "Split" configuration with $90^{\circ}$ hybrid, 2-port decoupler and resonant loops

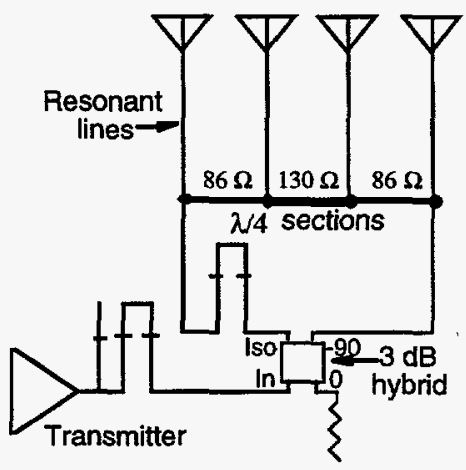

FIGURE 3. Traveling Wave Antenna (TWA) configuration of a 4element array [5].
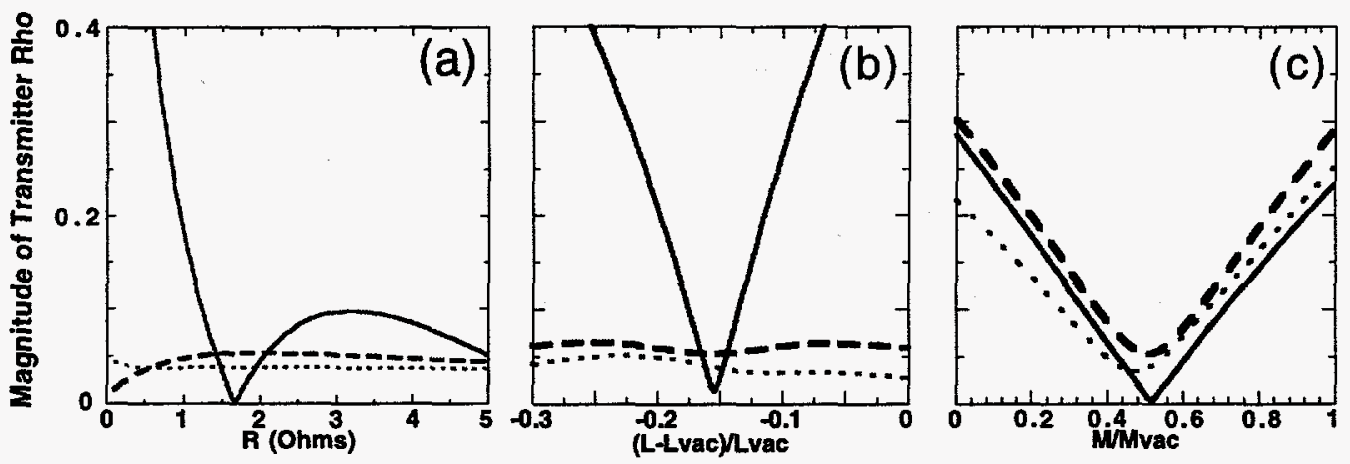

FIGURE 4. Voltage reflection coefficient seen by the generator for each configuration in $90^{\circ}$ phasing, with tuners fixed, as (a) $R$, (b) $L$, and (c) $M$ of the array elements are varied. Solid line: conventional, dashed line: split, and dotted line: TWA configuration.
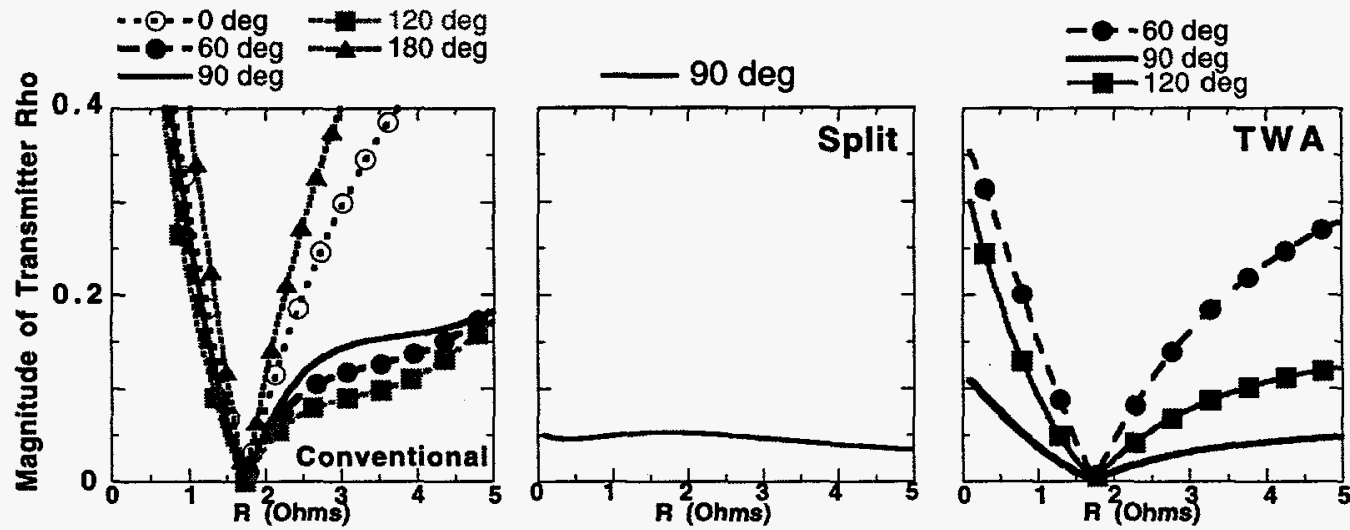

FIGURE 5. Scans of the antenna loading in each configuration at different antenna phasings. The self-inductance is assumed to vary with the resistive loading as $\Delta L / L_{v a c}$ $=-0.11-0.28^{*}(R / 1 \Omega)$ and the mutual inductance as $\Delta M / M_{\text {vac }}=0.63-0.07^{*}(R / 1 \Omega)$. 